\title{
Diaprepes Root Weevil on Southern Highbush Blueberry in Florida ${ }^{1}$
}

\author{
Douglas A. Phillips, Oscar E. Liburd, and Larry W. Duncan²
}

\section{Introduction}

Citrus root weevil, Diaprepes abbreviatus (Linnaeus), is a destructive pest on citrus trees. It is now becoming a significant pest on blueberry in central Florida, at times causing major damage to blueberry bushes that are more than two years old. The blue-green root weevil, Pachnaeus litus Germar, can also be found feeding on the roots of blueberry plants.

\section{Description and Life Cycle}

The Diaprepes root weevil (hereafter root weevil) has a life cycle consisting of egg, larva, pupa, and adult. Eggs are deposited by adults between two leaves, or within a folded leaf, held together by an excreted adhesive. The eggs are oblong-oval, smooth, and yellowish-white. Adult females live for 3-4 months, during which time they can lay up to 5,000 eggs. The eggs hatch in 7-8 days, and the larvae fall to the ground, burrow in the soil, and begin to feed on the roots. Larvae are white and legless and have chewing mouthparts. They reach a length of around one inch $(2.5$ $\mathrm{cm}$ ) (Figure 1). Adults emerge from the soil after pupating. They vary in color and scales on their wing covers can be black with white, red orange, and/or yellow. These scales can rub off of ridge tops, leaving the appearance of black stripes on a lighter background (Figure 2). Adult weevils vary in size from $3 / 8$ to $3 / 4$ inch $(1.1$ to $1.9 \mathrm{~cm})$ and feed on the margins of young leaves, resulting in a notching pattern that can sometimes be confused with grasshopper or caterpillar damage (Figure 3). The life cycle varies depending on environmental and nutritional factors. Larvae can feed for several months before pupating in the soil and then emerging as adults. Due to this extended feeding time and the 3-4 months during which the adults are laying eggs, the timing for one complete life cycle is difficult to predict.

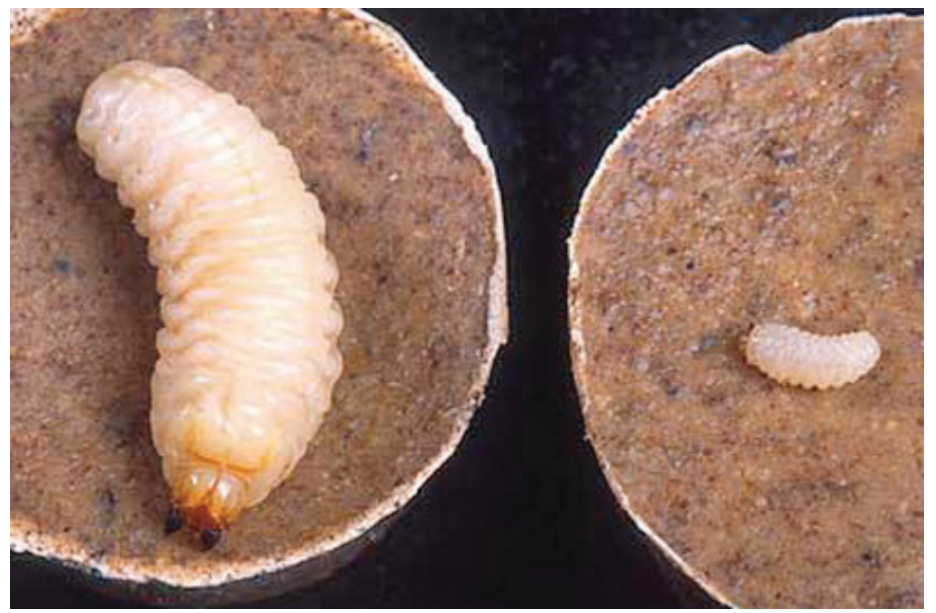

Figure 1. Diaprepes root weevil larvae.

Credits: Peggy Grub, USDA

1. This document is ENY999, one of a series of the Entomology and Nematology Department, UF/IFAS Extension. Original publication date April 2019. Visit the EDIS website at https://edis.ifas.ufl.edu for the currently supported version of this publication.

2. Douglas A. Phillips, blueberry Extension coordinator, Horticultural Sciences Department; Oscar E. Liburd, professor and program leader, fruit and vegetable entomology, Entomology and Nematology Department; and Larry W. Duncan, professor, Nematology, Entomology and Nematology Department; UF/IFAS Extension, Gainesville, FL 32611. 


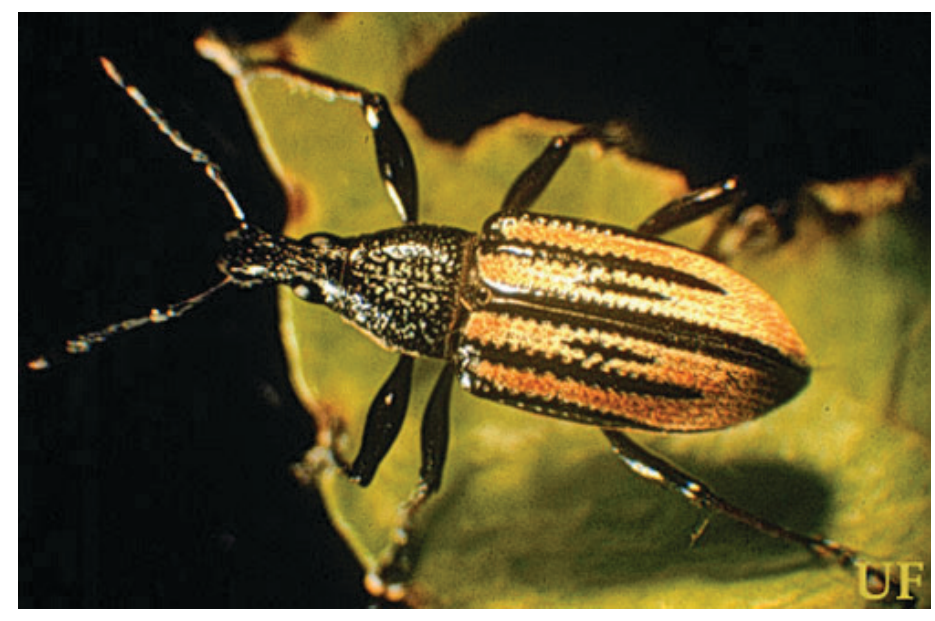

Figure 2. Adult Diaprepes root weevil.

Credits: Jorge Pena, UF/IFAS

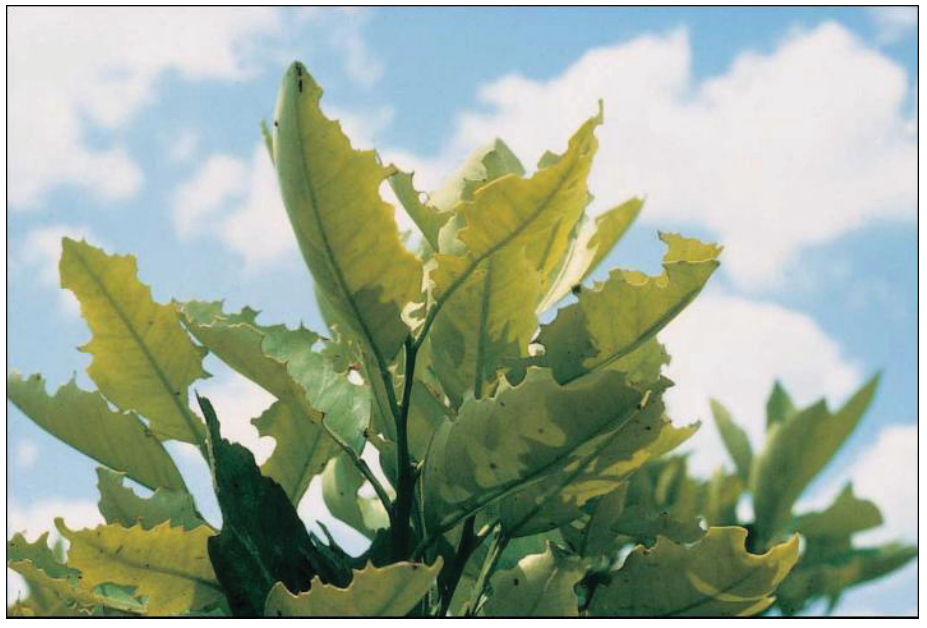

Figure 3. Adult root weevil notching damage on citrus leaves. Credits: UF/IFAS CREC

\section{Damage}

Root weevil larvae damage blueberry plants by feeding on the roots. Damage can include channeling and holes in the roots, and feeding injury and girdling near the crown (Figure 4). Note that this damage is frequently observed some period of time after the larvae begin to feed on the roots, and at that point damage near the crown can appear similar to the effects of root girdling or mechanical wounding and abrasion. These injuries can kill or cause serious decline in blueberry plants, and may also create an entry point for Phytophthora, causing a root rot infection.

\section{Monitoring and Control}

Adult root weevils are most active from May through October or November in central Florida, typically peaking in late May to early July. A second peak in late August to mid-October has been observed at times in citrus. Growers can scout for adult weevils by inspecting young foliage for a notching pattern. However, because this type of damage can also be caused by other insect pests, an additional monitoring method is placing plastic sheeting or a lightcolored drop cloth under the blueberry plant and shaking the branches to dislodge the adults. This will be most effective in early morning or late afternoon. There is no existing method for monitoring larvae in the soil.

Existing root weevil controls have primarily been developed and used in citrus. Although there are no published field studies of these controls on southern highbush blueberry in Florida, certain citrus controls may prove effective against this pest.

Management and control of root weevil should target both the adult and larval stages. Foliar insecticide sprays to control adults include Provado ${ }^{\oplus}$ (imidacloprid), Brigade ${ }^{\oplus}$ (bifenthrin), Danitol ${ }^{\circ}$ (fenpropathrin), and Actara ${ }^{\circ}$ (thiamethoxam). Foliar sprays should be applied every 10-14 days, and application should begin when 3 or more adults are found within 1-acre blocks. Larvae can be managed with insecticides either by directly drenching the soil area beneath the plant canopy or by applying them through drip or micro-jet irrigation systems. Insecticides that target larval populations are Admire ${ }^{\circledast}$ Pro (imidacloprid), Brigade ${ }^{\oplus}$, Danitol $^{\circledR}$, and Platinum ${ }^{\oplus}$ (thiamethoxam). Brigade ${ }^{\oplus}$ has been used in citrus as a spray application beneath the plant canopy to create an insecticide barrier to larvae dropping from plant foliage and entering the soil. Provado ${ }^{\circledR}$, Admire ${ }^{\oplus}$ Pro, Actara ${ }^{\circledR}$, and Platinum ${ }^{\circledast}$ are all neonicotinoids and should not follow each other in a rotation program. Preharvest intervals and other labeling instructions should be closely followed. Bifenthrin is not recommended to be used as a soil drench during harvest. Also, horticultural oil has been used in citrus to separate leaves protecting root weevil eggs, subjecting the eggs to desiccation and predation.

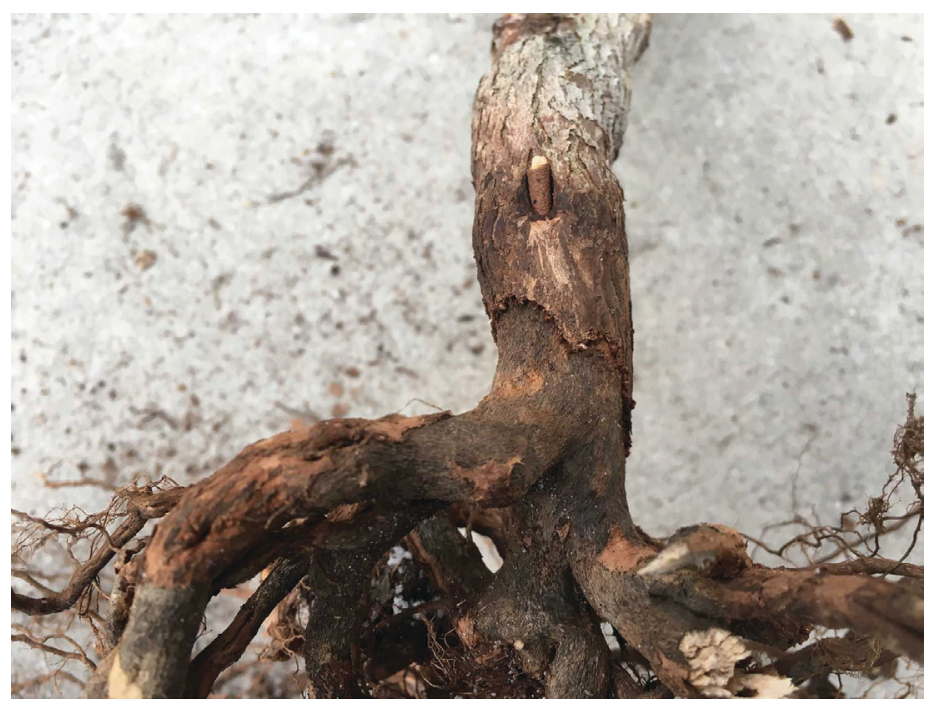

Figure 4. Diaprepes root weevil damage on blueberry. Credits: L. Park 
In addition, entomopathogenic nematodes may have potential for controlling root weevil larvae in blueberry. The Steinernema riobrave species (sold under the product name Nemasys R) has been shown to be an effective biocontrol in citrus, targeting root weevil larvae in the soil. Recent studies have shown that the drip irrigation systems frequently used in blueberry production are an effective distribution method for these nematodes. Because southern highbush blueberries are primarily grown in pine bark substrate (as opposed to the non-amended sandy soil in which citrus typically grows), studies are underway to screen additional nematode species for use in pine bark to determine efficacy against root weevil larvae.

\section{References}

Bender, G. S., L. M. Bates, J. A. Bethke, E. Lewis, G.

Tanizaki, J. G. Morse, and K. E. Godfrey. 2014. "Evaluation of Insecticides, Entomopathogenic Nematodes, and Physical Soil Barriers for Control of Diaprepes abbreviatus (Coleoptera: Curculionidae) in Citrus." J. Econ. Entomol. 107(6): 2137-2146.

Duncan, L. W., J. H. Graham, J. Zellers, D. Bright, D. C. Dunn, F. E. El-Borai, and D.L . Porazinska. 2007. "Food Web Responses to Augmenting the Entomopathogenic Nematodes in Bare and Animal Manure-Mulched Soil." J. Nematol. 39(2): 176-189.

Duncan, L. W., C. W. McCoy, and A. C. Terranova. 1996. "Estimating Sample Size and Persistence of Entomogenous Nematodes in Sandy Soils and Their Efficacy Against the Larvae of Diaprepes abbreviatus in Florida." J. Nematol. 28(1): 56-67. 